\title{
SYNTHESIS, REACTIONS AND ANTITUMOR EVALUATION OF SOME POLYCONDENSED THIAZOLOPYRIMIDINE DERIVATIVES
}

\author{
Nermin A. M. El-Seadawy
}

Department of Chemistry, Faculty of Science (Girls), Al-Azhar University, Nasr City, Cairo, Egypt

\begin{abstract}
Some novel thiazolo[3,2-a]pyrimidines, pyrimidino[1',2':3,2]thiazolo[4,5-b] pyridines,pyrimidino[1",2": $\left.3^{\prime}, 2^{\prime}\right]$ thiazolo[4',5':2,3]pyrido-[2,3-d]pyrimidines, pyrimidino $\left[1^{\prime}, 2^{\prime}: 3,2\right]$ thiazolo[4,5-d]pyrimidines, pyrimidino[1',2':3,2] thiazolo[4,5-d][1,2,4] triazolo[3,4b]pyrimidines (2-10) were prepared starting with 2-(arylmethylene) trimethylthiazolo [3,2a]pyrimidin-3-one(2). Also, some, S-alkylated thiazolo[4,5-d] pyrimidine derivatives were synthesized via reaction of 4-substited-7,7,9-trimethyl-1,3,4trihydropyrimidino[1',2':3,2] thiazolo[4,5-d]pyrimidin-2-thione (6b) with different reagents. Furthermore, some of the prepared products were selected and tested for activity against HCT116 and MCF-7 (human colon carcinoma and human breast carcinoma).
\end{abstract}

Keywords: Antitumor evaluation, thiazolopyrimidines, triazolopyrimidines.

\section{INTRODUCTION}

Fused thiazolo[4,5-d]pyrimidine derivatives are one of the most important classes of compounds because of their effective biological activity and their synthesis attracted great attention. (Beek, et al., 1999; Baxter, et al., 2006; Walter, et al., 2007). They bear structural resemblance to purine and several substituted thiazolo[4,5-d]pyrimidine (a guanosine analogue) exhibited in vivo activity against a variety of RNA and DNA viruses [Kini, et al., 1991) and human cytomegalovirus (HCMV) (Lewis, et al., 1995). Also, has antitumor antimetastatic properties (Nagahara, K., 1990). Recently, many of their derivatives have been synthesized as potential anticancer (Fahmy, et al., 2003), antiinflammatory activity (Bekhit, et al., 2003; Abdel-Megeid, et al., 2005), and antimicrobial activity (Bekhit, et al., 2003; Rashad, et al., 2005, Rashad et al., 2010). Besides, prominent biological activities have been reported for pyrmidine derivatives, such as antiviral (Hegab et al., 2006; Rashad, et al., 2007; Shamroukh, et al., 2010); antihypertensive (Shishoo, et al., 2000); antihistaminic (Ammar, et al., 2002); analgesic; (Amr, et al., 2003; Alagrasamy, et al., 2007; Wagnat, et al., 2008). In connection with our research program, for the synthesis of different fused hetrocyclic compounds having antitumor activity (HO, et al., 2003; Amr, et al., 2006), we describe here the synthesis of some new pyrimidino[1',2':3,2]thiazolo[4,5-d]pyrimidine derivatives hoping to show promising antitumor activity.

\section{RESULTS AND DISCUSSION}

With respect to the previous studies carried out in our laboratory, 2-thioxopyrimidine derivative 1, precurosors (Takeshima, et al., 1968) have been regarded as promising intermediates to produce thiazolopyrido pyrimidin-2,4-dithione derivatives $\mathbf{5}, \mathbf{a}, \mathbf{b}$ and thiazolo[4,5-d]pyrimidin-2-thione derivatives 6a-c which bear some structural analogies with natural nucleobases. The interaction of pyrimidin-2-thione derivative $\mathbf{1}$ with 
chloroacetic acid and aromatic aldehydes in the presence of acetic anhydride (Hamman, et al., 1981) led to the formation of 2-(arylmethylene) trimethylthiazolidino[3,2-a]pyrimidin-3one 2a-c (Scheme 1). The structures of compounds 2a-c were deduced from elemental analysis and spectral data. Compound $\mathbf{2 b}$ as an example: its IR spectrum showed absorption band at $1706 \mathrm{~cm}^{-1}\left(v_{\mathrm{CO}}\right)$; moreover, ${ }^{1} \mathrm{H}$ NMR spectrum showed signals at $7.36 \mathrm{ppm}(\mathrm{s}$, $1 \mathrm{H},=\mathrm{CH}-\mathrm{Ar})$ and 7.80-7.99 (m, 4H, ArH).

Interaction of compound $\mathbf{2 a , b}$ with malononitrile in acetic acid in the presence of ammonium acetate under reflux led to the formation of enaminonitrile derivatives $\mathbf{3 a}, \mathbf{b}$ (Scheme 1). The IR spectrum of compound 3a showed the presence of bands characteristic for a cyano group at $2193 \mathrm{~cm}^{-1}$ and amino group at $3209 \& 3344 \mathrm{~cm}^{-1}$. The pyrimidin-2,4dithione derivatives 5a,b were obtained by refluxing of $\mathbf{3 a}, \mathbf{b}$ with carbon disulfide in dry pyridine (Hefez, et al. 2010) as shown in (Scheme 1). The proposed structure was confirmed by spectral data. The IR spectrum of $\mathbf{5 a}$ revealed the absence of a band characteristic for the cayno group, moreover, the ${ }^{13} \mathrm{C}$ NMR spectrum showed signal at $\delta 176.13 \& 176.87 \mathrm{ppm}$ corresponding to the two thione groups.<smiles>CC1=CC(C)(C)NC(=S)N1</smiles>

1

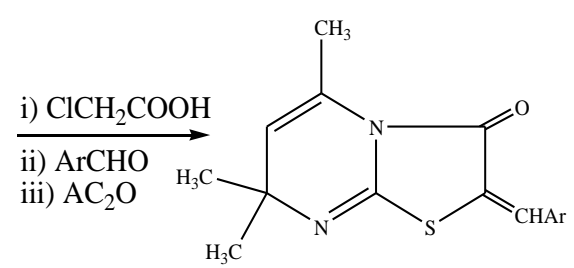

2<smiles>CC1=CC(C)(C)N=C2Sc3c(nc(N)c(Cl)c3[Al])N12</smiles>

3

$$
\downarrow \begin{aligned}
& \mathrm{a}=4-\mathrm{C}_{6} \mathrm{H}_{4}-\mathrm{Br} \\
& \mathrm{b}=3-\mathrm{C}_{6} \mathrm{H}_{4}-\mathrm{NO}_{2} \\
& \mathrm{CS}_{2} / \text { Pyridine }
\end{aligned}
$$<smiles></smiles><smiles>CC1=CC(C)(C)N=C2Sc3c(nc4c(c3N)C(=N)NC4=S)N12</smiles>

4a,b

Scheme 1

2-Arylmethyelene thiazolidinopyrimidin-3-one 2a-c was considered as the versatile precursor to synthesis of other 2-thioxopyrimidine derivatives in good yield. When compounds 2a-c were treated with thiourea in ethanol under reflux, it afforded the corresponding thiazolo[4,5-d]pyrimidin-2-thione derivatives 6a-c. (Scheme 2). 


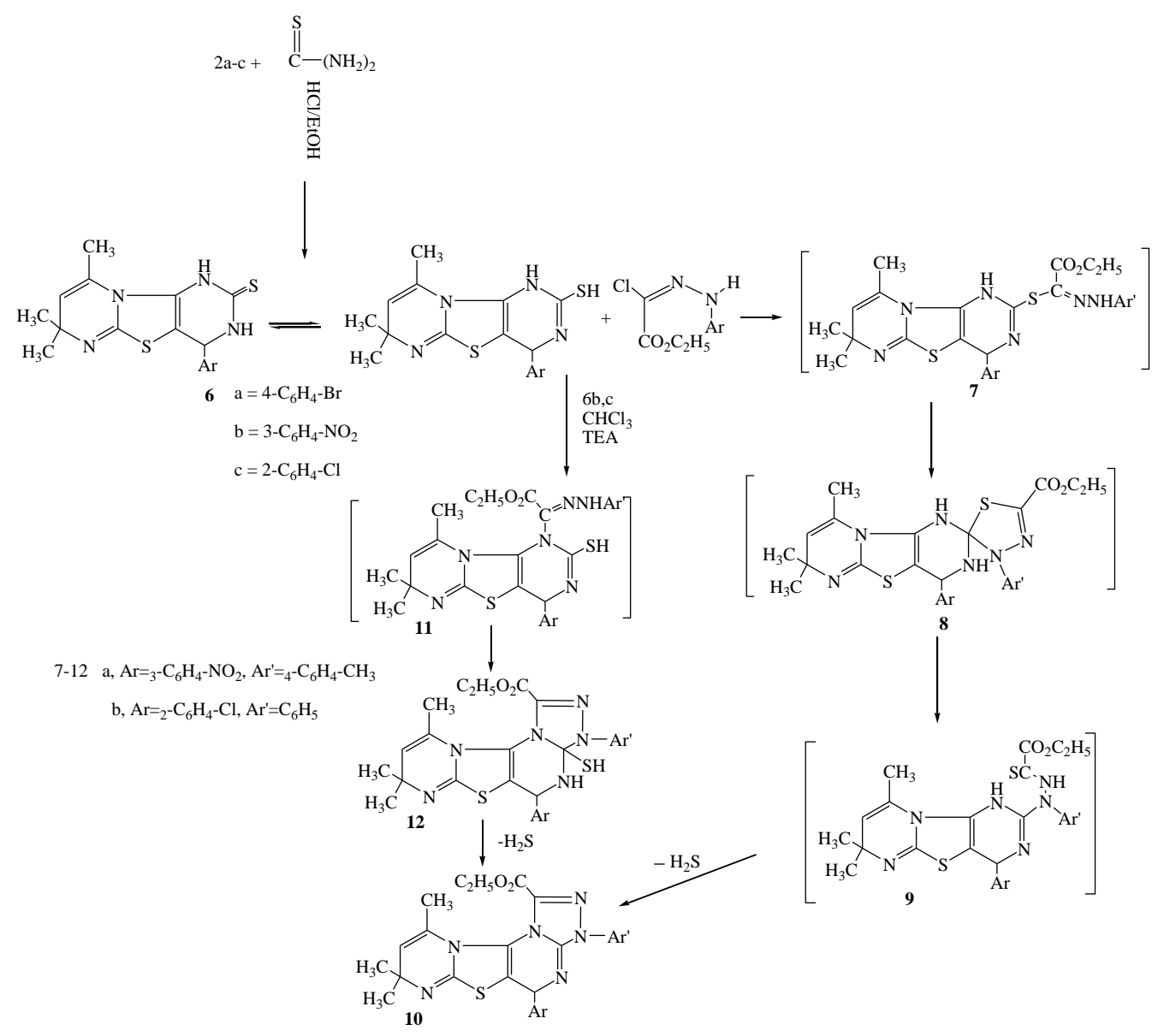

Scheme 2

The structures of these compounds were confirmed with elemental analysis and spectral data. Compound 6a as an example: its IR spectrum showed absorption bands at 3166.8 and $3273.8 \mathrm{~cm}^{-1}(2 \mathrm{NH}) ;{ }^{13} \mathrm{C}$ NMR spectrum of $\mathbf{6 b}$ revealed the presence of $(\mathrm{C}=\mathrm{S})$ at $173.43 \mathrm{ppm}$. Compounds 6a-c were found to be useful for the syntheses of the interesting $[1,2,4]$ triazolopyrimidines. Thus , two possible pathways can be accounted for the formaiotn of compound 10:1). the 1,3-dipolar cycloaddition of the thiol tautomer $\mathbf{6}$ to the nitrilium imide, generated in situ from hydrazonyl halides and triethylamine in dry chloroform gave the thiohydrazonate ester 7 which underwent nucleophilic cyclization to yield the spiro compound $\mathbf{8}$ followed by opening ring to give $\mathbf{9}$ which cyclized to yield $\mathbf{1 0}$ by loss of hydrogen sulfide: 2)1,3-dipolar cycloaddition of the nitrilium imide to the $\mathrm{C}=\mathrm{S}$ double bond of $\mathbf{6}$ can give hydrazontester $\mathbf{1 1}$ which then cyclized to give intermediate $\mathbf{1 2}$ which in turn gave compound $\mathbf{1 0}$ by loss of hydrogen sulfide (scheme 2). All attempts to isolate any intermediates were unsuccessful. Structures of $\mathbf{1 0 a , b}$ were elucidated on the basis of elemental analysis, spectral data and alternative synthetic route (Abdelhamid, et al., 2007; Hafez, et al., 2010). Compound 10a as an example, IR spectrum showed absorption band at $1748 \mathrm{~cm}^{-1}(\mathrm{C}=\mathrm{O}$ ester $)$ and ${ }^{1} \mathrm{H}-\mathrm{NMR}$ spectrum revealed signals at $\delta 1.24 \mathrm{ppm}(\mathrm{t}, \mathrm{J}=7.5 \mathrm{~Hz}$, $\left.3 \mathrm{H}, \mathrm{CH}_{3}\right), 4.17\left(\mathrm{q}, \mathrm{J}=7.5 \mathrm{~Hz}, 2 \mathrm{H}, \mathrm{CH}_{2}\right.$ ) (c.f. Experimental). Furthermore, alkylation of compound $\mathbf{6 b}$ with chloroethanol in alcoholic sodium hydroxide gave 2-(4-(m-nitrophenyl)7,7,9-trimethyl-1,4-dihydropyrimidino[1',2':3,2] thiazolo[4,5-d]pyrimidin-2-

ylsulfanyl)ethanol (13). (Scheme 3). The structure of the formed compound was established by its elemental analysis and spectral data (IR \& ${ }^{1} \mathrm{H}$ NMR). ${ }^{1} \mathrm{H}$ NMR spectrum showed signals at $\delta 4.19-4.21 \mathrm{ppm}\left(\mathrm{m}, 4 \mathrm{H}, 2 \mathrm{CH}_{2}\right), 5.01\left(\mathrm{~s}, 1 \mathrm{H}, \mathrm{OH}\right.$, exchangeable with $\left.\mathrm{D}_{2} \mathrm{O}\right)$. Cyanoethylation of compound $\mathbf{6} \mathbf{b}$ with acrylonitrile in ethanol and triethyl amine afforded 
Michael type adduct 2-(2-cyanoethylsulfanyl)-7,7,9-trimethyl-4-(m-nitrophenyl)-1,4dihydropyrimidino[1',2':3,2] thiazolo[4,5-d]pyrimidine (14). Cyclization of the latter compound with salicyladehyde or 7-hydroxy-5-methoxy-2-oxo-benzopyran-6-carboxaldehyde in ethanolic piperidine yielded the cyclized 2-iminobenzopyran and 2iminobenzodipyran derivatives (15) and (16) respectively (scheme 3). The structures of compounds 14-16 were confirmed on the basis of their elemental and spectral data. Their IR spectra showed the absence of the absorption band at $2243 \mathrm{~cm}^{-1}$ characteristic for $(\mathrm{C} \equiv \mathrm{N})$ of compound 14 and presence $(\mathrm{NH} / \mathrm{C}=\mathrm{O})$ groups in IR spectrum of compound 16 and the $\mathrm{NH}-$ proton $\left(\mathrm{D}_{2} \mathrm{O}\right.$ exchangeable in the ${ }^{1} \mathrm{H}-\mathrm{NMR}$ spectra of compounds 15 and 16 (c.f. Exp.)

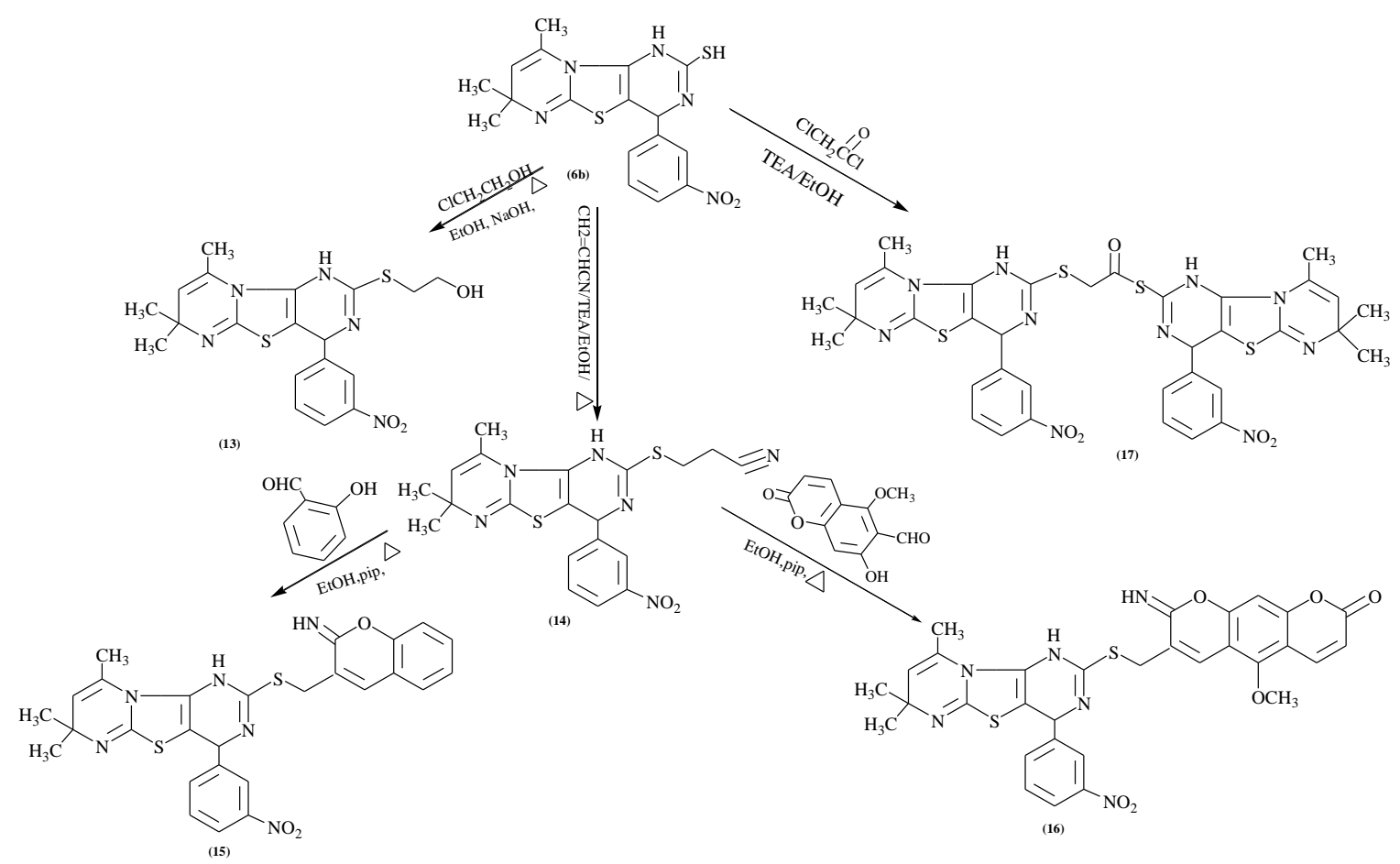

Scheme (3)

On the other hand, alkylation of compound $\mathbf{6 b}$ with chloroacetyl chloride in the presence of triethylamine and dimethyl formamide gave 4-(m-nitrophenyl)-7,7,9-trimethyl1,4-dihydropyrimidino[1',2':3,2] thiazolo[4,5-d]pyrimidine-2-ylsulfanyl)-2-(4-m-nitrophenyl) -7,7,9-trimethyl-1,4-dihydropyrimidino[1',2':3,2]thiazolo[4,5-d]pyrimidine-2-ylsulphanyl) ethanethioate (17). Dehydrohalogenation took place joining two molecules of compound $\mathbf{6 b}$. Inspection of the IR spectrum of the reaction product $\mathbf{1 7}$ revealed the presence of the $\mathrm{C}=\mathrm{O}$ group and its mass spectrum exhibited a molecular ion peak $\mathrm{M}^{+}$at $\mathrm{m} / \mathrm{z}: 814$ (12.7\%) (c.f. Experimental).

\section{PHARMACOLOGY}

Antitumor effect

\section{CONCLUSION}

The newly synthesized compounds $\mathbf{2 b}$ and $\mathbf{1 3}$ were tested for antitumor activity and they exhibited a high significant anticancer activity against both of HCT 116cell line and MCF-7 cell line (human colon carcinoma cell and human breast carcinoma cell). The results are summarized in Figures. 1-4. 
Evaluation of cytotoxicity effect 2-(m-nitrobenzylidine)-5,7,7-trimethylthizolidino[3,2a] pyrimidin-3-one (2b) against HCT 116 cell line

\begin{tabular}{|c|c|}
\hline $\begin{array}{c}\text { Sample } \\
\text { conc. }(\mu \mathrm{g})\end{array}$ & Viability \% \\
\hline 50 & 30.93 \\
\hline 25 & 63.32 \\
\hline 12.5 & 77.01 \\
\hline 6.25 & 84.98 \\
\hline 3.125 & 96.54 \\
\hline 1.56 & 98.83 \\
\hline 0 & 100.00 \\
\hline
\end{tabular}

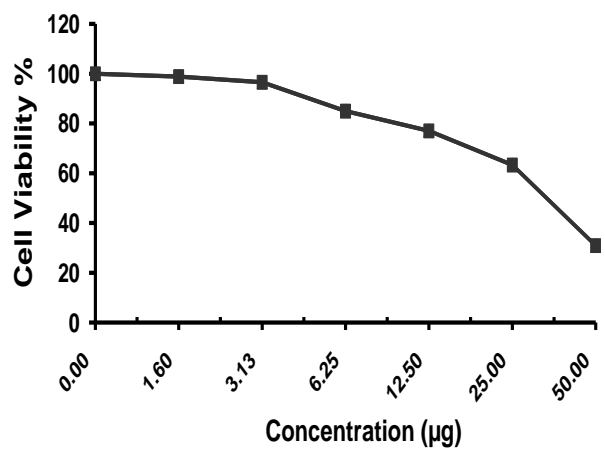

Comment:

Fig (1)

Inhibitory activity against colon carcinoma cells was detected under these experimental conditions with $\mathrm{IC}_{50}=35.3 \mu \mathrm{g}$.

Evaluation of cytotoxicity effect 2-(m-nitrobenzylidine)-5,7,7-trimethylthizolidino [3,2a] pyrimidin-3-one (2b) against MCF-7 cell line

\begin{tabular}{|c|c|}
\hline $\begin{array}{c}\text { Sample } \\
\text { conc. }(\mu \mathrm{g})\end{array}$ & $\begin{array}{l}\text { Viability } \\
\%\end{array}$ \\
\hline 50 & 47.55 \\
\hline 25 & 76.96 \\
\hline 12.5 & 88.58 \\
\hline 6.25 & 93.14 \\
\hline 3.125 & 97.52 \\
\hline 1.56 & 100 \\
\hline 0 & 100.00 \\
\hline \multicolumn{2}{|c}{} \\
\hline
\end{tabular}

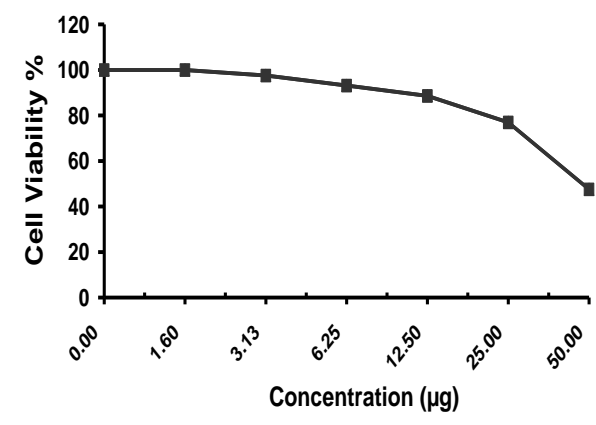

Fig (2)

\section{Comment:}

Inhibitory activity against breast carcinoma cells was detected under these experimental conditions with $I C_{50}=47.9 \mu g$.

Evaluation of cytotoxicity effect 2-(4-(m-nitrophenyl)-7,7,9-trimethyl-1,4dihydropyrimidino $\left[1^{\prime}, 2^{\prime}: 3,2\right]$ thiazolo $[4,5-d]$ pyrimidine-2-yl sulfanyl)ethanol against HCT 116 cell line

\begin{tabular}{|c|c|}
\hline $\begin{array}{c}\text { Sample conc. } \\
(\mu \mathrm{g})\end{array}$ & Viability \% \\
\hline 50 & 6.44 \\
\hline 25 & 14.95 \\
\hline 12.5 & 22.70 \\
\hline 6.25 & 35.68 \\
\hline 3.125 & 47.42 \\
\hline 1.56 & 55.39 \\
\hline 0 & 100.00 \\
\hline
\end{tabular}

\section{Comment:}

Inhibitory activity against colon carci

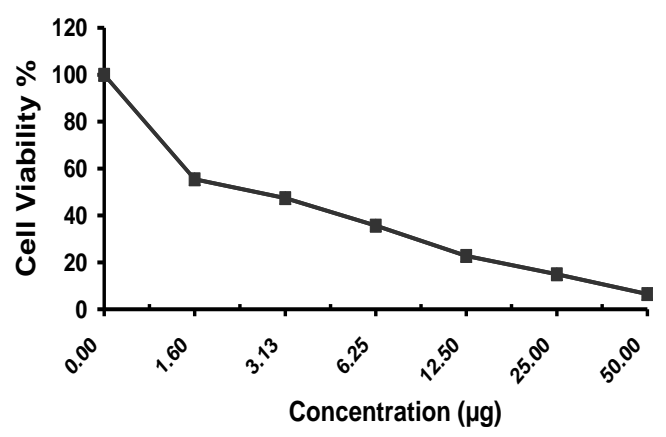

Fig. (3) conditions with $I C_{50}=2.2 \mu \mathrm{g}$. 
Evaluation of cytotoxicity effect of 2-(4-(m-nitrophenyl)-7,7,9-trimethyl-1,4dihydropyrimidino $\left[1^{\prime}, 2^{\prime}: 3,2\right]$ thiazolo $[4,5-d]$ pyrimidine-2-yl sulfanyl)ethanol (13) against MCF-7 cell line

\begin{tabular}{|c|c|}
\hline $\begin{array}{c}\text { Sample } \\
\text { conc. }(\boldsymbol{\mu g})\end{array}$ & Viability \% \\
\hline 50 & 8.94 \\
\hline 25 & 17.21 \\
\hline 12.5 & 28.97 \\
\hline 6.25 & 34.66 \\
\hline 3.125 & 45.18 \\
\hline 1.56 & 56.32 \\
\hline 0 & 100.00 \\
\hline
\end{tabular}

\section{Comment:}

Inhibitory activity against breast carcmoma ceus was aeıcciea unaer ınese experımenual conditions with $I C_{50}=2.4 \mu \mathrm{g}$.

Table (1) Characterization data of compounds 2-17.

\begin{tabular}{|c|c|c|c|c|c|c|c|c|}
\hline $\begin{array}{l}\text { Comp. } \\
\text { No. }\end{array}$ & $\begin{array}{l}\text { M.P. } \\
{\left[{ }^{\circ} \mathrm{C}\right]}\end{array}$ & $\begin{array}{c}\text { Yield } \\
\text { [\%] } \\
\text { solvent }\end{array}$ & $\begin{array}{c}\text { Mol formula } \\
\text { (mol. Wt })\end{array}$ & $\begin{array}{c}\mathrm{C} \% \\
\text { calcd./found }\end{array}$ & $\begin{array}{c}\text { Analysis H } \\
\% \\
\text { calcd./found }\end{array}$ & N\% & S\% & $\mathrm{Br}$ \\
\hline $2 a$ & $231-232$ & $\begin{array}{c}85 \\
\mathrm{~B}\end{array}$ & $\begin{array}{c}\mathrm{C}_{16} \mathrm{H}_{15} \mathrm{~N}_{2} \mathrm{OBrS} \\
363.27\end{array}$ & $\begin{array}{l}52.90 \\
52.87\end{array}$ & $\begin{array}{l}4.16 \\
4.14\end{array}$ & $\begin{array}{l}7.71 \\
7.69\end{array}$ & $\begin{array}{l}8.83 \\
8.80\end{array}$ & $\begin{array}{c}22.0 \\
21.97\end{array}$ \\
\hline $2 \mathrm{~b}$ & $247-249$ & $\begin{array}{l}80 \\
\mathrm{M}\end{array}$ & $\begin{array}{c}\mathrm{C}_{16} \mathrm{H}_{15} \mathrm{~N}_{3} \mathrm{O}_{3} \mathrm{~S} \\
329 \\
\end{array}$ & $\begin{array}{l}58.34 \\
58.37 \\
\end{array}$ & $\begin{array}{l}4.59 \\
4.65 \\
\end{array}$ & $\begin{array}{l}12.76 \\
12.78 \\
\end{array}$ & $\begin{array}{l}9.74 \\
9.75 \\
\end{array}$ & -- \\
\hline $2 c$ & $211-212$ & $\begin{array}{l}65 \\
\mathrm{~B} \\
\end{array}$ & $\begin{array}{c}\mathrm{C}_{16} \mathrm{H}_{15} \mathrm{~N}_{2} \mathrm{OSCl} \\
318.82 \\
\end{array}$ & $\begin{array}{l}60.28 \\
60.15 \\
\end{array}$ & $\begin{array}{l}4.74 \\
4.70 \\
\end{array}$ & $\begin{array}{l}8.79 \\
8.85 \\
\end{array}$ & $\begin{array}{l}10.06 \\
10.12 \\
\end{array}$ & $\begin{array}{c}11.12(\mathrm{Cl}) \\
11.07 \\
\end{array}$ \\
\hline $3 a$ & $192-193$ & $\begin{array}{r}90 \\
\mathrm{~B} \\
\end{array}$ & $\begin{array}{c}\mathrm{C}_{19} \mathrm{H}_{16} \mathrm{~N}_{5} \mathrm{BrS} \\
426.33\end{array}$ & $\begin{array}{l}53.53 \\
53.49 \\
\end{array}$ & $\begin{array}{l}3.78 \\
3.76 \\
\end{array}$ & $\begin{array}{l}16.43 \\
16.48 \\
\end{array}$ & $\begin{array}{l}7.52 \\
7.49 \\
\end{array}$ & $\begin{array}{l}18.74 \\
18.82 \\
\end{array}$ \\
\hline $3 b$ & $181-183$ & $\begin{array}{c}95 \\
\mathrm{~B}\end{array}$ & $\begin{array}{c}\mathrm{C}_{19} \mathrm{H}_{16} \mathrm{~N}_{6} \mathrm{O}_{2} \mathrm{~S} \\
392.43\end{array}$ & $\begin{array}{l}58.15 \\
58.12\end{array}$ & $\begin{array}{l}4.11 \\
4.19\end{array}$ & $\begin{array}{l}21.42 \\
21.39\end{array}$ & $\begin{array}{l}8.17 \\
8.14\end{array}$ & -- \\
\hline $5 a$ & $243-244$ & $\begin{array}{c}70 \\
\mathrm{E}\end{array}$ & $\begin{array}{c}\mathrm{C}_{20} \mathrm{H}_{16} \mathrm{~N}_{5} \mathrm{BrS}_{3} \\
502.47\end{array}$ & $\begin{array}{l}47.81 \\
47.83 \\
\end{array}$ & $\begin{array}{l}3.21 \\
3.18 \\
\end{array}$ & $\begin{array}{l}13.94 \\
13.90\end{array}$ & $\begin{array}{l}19.14 \\
19.16\end{array}$ & $\begin{array}{l}15.90 \\
15.88\end{array}$ \\
\hline $5 b$ & $251-253$ & $\begin{array}{l}75 \\
\mathrm{M} \\
\end{array}$ & $\begin{array}{c}\mathrm{C}_{20} \mathrm{H}_{16} \mathrm{~N}_{6} \mathrm{O}_{2} \mathrm{~S}_{3} \\
468.58\end{array}$ & $\begin{array}{l}51.26 \\
51.24 \\
\end{array}$ & $\begin{array}{l}3.44 \\
3.41 \\
\end{array}$ & $\begin{array}{l}17.94 \\
17.90 \\
\end{array}$ & $\begin{array}{l}20.53 \\
20.50 \\
\end{array}$ & -- \\
\hline $6 a$ & $172-173$ & $\begin{array}{l}85 \\
\mathrm{~B} \\
\end{array}$ & $\begin{array}{c}\mathrm{C}_{17} \mathrm{H}_{17} \mathrm{~N}_{4} \mathrm{BrS}_{2} \\
421.38 \\
\end{array}$ & $\begin{array}{l}48.46 \\
48.44 \\
\end{array}$ & $\begin{array}{c}40.70 \\
4.91 \\
\end{array}$ & $\begin{array}{l}13.30 \\
13.73 \\
\end{array}$ & $\begin{array}{l}15.22 \\
15.20 \\
\end{array}$ & $\begin{array}{l}18.96 \\
18.98 \\
\end{array}$ \\
\hline $6 b$ & $187-188$ & $\begin{array}{c}90 \\
\mathrm{~B}\end{array}$ & $\begin{array}{c}\mathrm{C}_{17} \mathrm{H}_{17} \mathrm{~N}_{5} \mathrm{O}_{2} \mathrm{~S}_{2} \\
387.48\end{array}$ & $\begin{array}{l}52.69 \\
52.76 \\
\end{array}$ & $\begin{array}{l}4.42 \\
4.39 \\
\end{array}$ & $\begin{array}{l}18.07 \\
18.04 \\
\end{array}$ & $\begin{array}{l}16.55 \\
16.52 \\
\end{array}$ & -- \\
\hline $6 c$ & $169-170$ & $\begin{array}{l}70 \\
\mathrm{~B} \\
\end{array}$ & $\begin{array}{c}\mathrm{C}_{17} \mathrm{H}_{17} \mathrm{~N}_{4} \mathrm{ClS}_{2} \\
376.93 \\
\end{array}$ & $\begin{array}{l}54.17 \\
54.14 \\
\end{array}$ & $\begin{array}{l}4.55 \\
4.56 \\
\end{array}$ & $\begin{array}{l}14.86 \\
14.80 \\
\end{array}$ & $\begin{array}{l}17.01 \\
17.07 \\
\end{array}$ & $\begin{array}{l}9.41 \\
9.48 \\
\end{array}$ \\
\hline $10 \mathrm{a}$ & $231-334$ & $\begin{array}{c}65 \\
\mathrm{E}\end{array}$ & $\begin{array}{c}\mathrm{C}_{28} \mathrm{H}_{27} \mathrm{~N}_{7} \mathrm{O}_{4} \mathrm{~S} \\
557.63\end{array}$ & $\begin{array}{l}60.31 \\
60.37 \\
\end{array}$ & $\begin{array}{l}4.88 \\
4.85 \\
\end{array}$ & $\begin{array}{l}17.58 \\
17.55 \\
\end{array}$ & $\begin{array}{l}5.75 \\
5.72 \\
\end{array}$ & -- \\
\hline $10 \mathrm{~b}$ & $249-251$ & $\begin{array}{l}79 \\
\mathrm{E}\end{array}$ & $\begin{array}{c}\mathrm{C}_{27} \mathrm{H}_{25} \mathrm{~N}_{6} \mathrm{O}_{2} \mathrm{ClS} \\
533.04\end{array}$ & $\begin{array}{l}60.84 \\
60.81 \\
\end{array}$ & $\begin{array}{l}4.73 \\
4.70 \\
\end{array}$ & $\begin{array}{l}15.77 \\
15.78 \\
\end{array}$ & $\begin{array}{l}6.02 \\
6.00 \\
\end{array}$ & $\begin{array}{c}6.65(\mathrm{Cl}) \\
6.61 \\
\end{array}$ \\
\hline 13 & $265-267$ & $\begin{array}{l}70 \\
\mathrm{~A}\end{array}$ & $\begin{array}{c}\mathrm{C}_{19} \mathrm{H}_{21} \mathrm{~N}_{5} \mathrm{O}_{3} \mathrm{~S}_{2} \\
431.53\end{array}$ & $\begin{array}{l}52.88 \\
52.89 \\
\end{array}$ & $\begin{array}{l}4.91 \\
4.88 \\
\end{array}$ & $\begin{array}{l}16.23 \\
16.20 \\
\end{array}$ & $\begin{array}{l}14.86 \\
14.19 \\
\end{array}$ & -- \\
\hline 14 & $243-245$ & $\begin{array}{l}85 \\
\mathrm{E}\end{array}$ & $\begin{array}{c}\mathrm{C}_{20} \mathrm{H}_{20} \mathrm{~N}_{6} \mathrm{O}_{2} \mathrm{~S}_{2} \\
440.11 \\
\end{array}$ & $\begin{array}{l}54.53 \\
54.50 \\
\end{array}$ & $\begin{array}{l}4.58 \\
4.60 \\
\end{array}$ & $\begin{array}{l}19.08 \\
19.15 \\
\end{array}$ & $\begin{array}{l}14.56 \\
14.53 \\
\end{array}$ & -- \\
\hline 15 & $169-170$ & $\begin{array}{l}75 \\
\mathrm{~B} \\
\end{array}$ & $\begin{array}{c}\mathrm{C}_{27} \mathrm{H}_{24} \mathrm{~N}_{6} \mathrm{O}_{3} \mathrm{~S}_{2} \\
544.65\end{array}$ & $\begin{array}{l}59.54 \\
59.41 \\
\end{array}$ & $\begin{array}{l}4.44 \\
4.41 \\
\end{array}$ & $\begin{array}{l}15.43 \\
15.40 \\
\end{array}$ & $\begin{array}{l}11.77 \\
11.74 \\
\end{array}$ & -- \\
\hline 16 & $178-179$ & $\begin{array}{c}80 \\
\mathrm{~B} \\
\end{array}$ & $\begin{array}{c}\mathrm{C}_{31} \mathrm{H}_{26} \mathrm{~N}_{6} \mathrm{O}_{6} \mathrm{~S}_{2} \\
642.7 \\
\end{array}$ & $\begin{array}{l}57.93 \\
57.96 \\
\end{array}$ & $\begin{array}{l}4.08 \\
4.15 \\
\end{array}$ & $\begin{array}{l}13.08 \\
13.19 \\
\end{array}$ & $\begin{array}{l}9.89 \\
9.91 \\
\end{array}$ & -- \\
\hline 17 & $181-183$ & $\begin{array}{l}75 \\
\mathrm{E}\end{array}$ & $\begin{array}{c}\mathrm{C}_{36} \mathrm{H}_{34} \mathrm{~N}_{10} \mathrm{O}_{4} \mathrm{~S}_{4} \\
814.96 \\
\end{array}$ & $\begin{array}{l}52.60 \\
51.67 \\
\end{array}$ & $\begin{array}{l}4.70 \\
4.67 \\
\end{array}$ & $\begin{array}{l}17.81 \\
17.77 \\
\end{array}$ & $\begin{array}{l}18.12 \\
18.09 \\
\end{array}$ & -- \\
\hline
\end{tabular}

Solvent of crystallization A: Acetone , B : benzene , M : methanol, E: ethanol 


\section{EXPERIMENTAL}

Melting points were recorded on an electrothermal IA 9100 digital melting point apparatus and were uncorrected. IR spectra $\left(\mathrm{V}_{\max }\right.$ in $\left.\mathrm{cm}^{-1}\right)$ were recorded on a Shimadzu FTIR 8300 spectrophotometer using $\mathrm{KBr}$ pellets technique. ${ }^{1} \mathrm{H}-\mathrm{NMR}$ and ${ }^{13} \mathrm{C}-\mathrm{NMR}$ spectra were recorded using Bruker WM-400 spectrophotometer using DMSO- $\mathrm{d}_{6}$ as the solvent and TMS as the internal reference (chemist shifts in ppm). The mass spectra were run at $70 \mathrm{eV}$ with a finnigan SSQ7000 spectrophotometer (thermo-instrument system incorporation, USA) Elemental analysis were operated using Mario El Mentar apparatus, Organic microanalysis unit. Elemental analysis and the above spectra were measured the at National Research Center. Pharmacology was carried out in the Regional Center for Mycology \& Biotechnology, Al-Azhar University.

\section{2-Arylidine-5,7,7-trimethyl thiazolidino[3,2-a]pyrimidin-3-one (2a-c).}

General procedure: A mixture of compound $1(0.01 \mathrm{~mol})$, chloroacetic acid $(0.01$ mol), aromatic aldehyde $(0.01 \mathrm{~mol})$ and $2 \mathrm{gm}$ of fused sodium acetate in $10 \mathrm{~mL}$ of acetic acid and $5 \mathrm{~mL}$ of acetic anhydride was refluxed for $1 \mathrm{~h}$. The reaction mixture was allowed to cool and then poured into cold water, the product obtained was filtered, dried and recrystalized from the proper solvent to give 2a-c.

2-(p-Bromobenzylidine)-5,7,7-trimethyl thiazolidino[3,2-a] pyrimidine-3-one (2a).

It was obtained from 1 and p-bromobenzaldehyde; IR $\left(\mathrm{cm}^{-1}, \mathrm{v}\right): 1703(\mathrm{CO}) ;{ }^{1} \mathrm{H}-$ NMR (DMSO-d $\left.\mathrm{d}_{6}, \delta, \mathrm{ppm}\right): 1.31,1.37,1.69\left(3 \mathrm{~s}, 9 \mathrm{H}, \mathrm{C}_{-7} 2 \mathrm{CH}_{3}, \mathrm{C}_{-5} \mathrm{CH}_{3}\right), 5.19\left(\mathrm{~s}, 1 \mathrm{H}, \mathrm{C}_{-6} \mathrm{H}\right)$, 7.41-7.81(m, $5 \mathrm{H}, 1 \mathrm{H}=\mathrm{CH}-+4 \mathrm{HArH})$.

\section{2-(m-Nitrobenzylidine)-5,7,7-trimethyl thiazolidino[3,2-a]pyrimidin 3-one (2b)}

It was obtained from compound 1 and m-nitrobenzaldehyde; IR $\left(\mathrm{cm}^{-1}, v\right) 1706(\mathrm{CO}) ;{ }^{1} \mathrm{H}-$ NMR (DMSO-d 6 , $\delta, p p m): 1.46,1.50,1.78\left(3 \mathrm{~s}, 9 \mathrm{H}_{2} \mathrm{C}_{-7} 2 \mathrm{CH}_{3}, \mathrm{C}_{-5} \mathrm{CH}_{3}\right), 5.7\left(\mathrm{~s}, 1 \mathrm{H}, \mathrm{C}_{-6} \mathrm{H}\right)$, $7.36(\mathrm{~s}, 1 \mathrm{H},=\mathrm{CH}-\mathrm{Ar}), 7.80-7.99(\mathrm{~m}, 4 \mathrm{H}, \mathrm{Ar}-\mathrm{H})$.

\section{2- (o-Chlorobenzylidine)-5,7,7-trimethyl thiazolidino[3,2-a]pyrimidin -3-one (2c).}

It was obtained from 1 and o-chlorobenzaldehyde; ${ }^{1} \mathrm{H}$ NMR (DMSO-d ${ }_{6}, \delta, p p m$ ) $1.50,1.62,1.80\left(3 \mathrm{~s}, 9 \mathrm{H}, \mathrm{C}_{-7} 2 \mathrm{CH}_{3}, \mathrm{C}_{-5} \mathrm{CH}_{3}\right), 5.54\left(\mathrm{~s}, 1 \mathrm{H}, \mathrm{C}_{-6} \mathrm{H}\right), 7.25(\mathrm{~s}, 1 \mathrm{H},=\mathrm{CH}-\mathrm{Ar}), 7.81-$ $7.87(\mathrm{~m}, 4 \mathrm{H}, \mathrm{ArH})$

\section{2-Amino-4-substituted-7,7,9-trimethylpyrimidino [1',2':3,2] thiazolo[4,5-b]pyridin-3-} carbonitrile $(\mathbf{3 a}, \mathbf{b})$.

\section{General procedure:}

A mixture of compound $2 \mathbf{a}$ or $2 \mathbf{b}(0.01 \mathrm{~mol})$, malononitrile $(0.01 \mathrm{~mol})$ and ammonium acetate $(0.02 \mathrm{~mol})$ in glacial acetic acid $(30 \mathrm{~mL})$ was heated under reflux for $6 \mathrm{~h}$., left at room-temperature, then poured into cold water. The solid product was filtered off, washed with water, dried and recrystallized to give compound $\mathbf{3 a}, \mathbf{b}$.

\section{2-Amino-4-(p-bromophenyl)-7,7,9-trimethyl pyrimidino[1',2':3,2] thiazolo[4,5-b] pyridine-3-carboitrile (3a).}

IR $\left(\mathrm{cm}^{-1}, \mathrm{v}\right): 2193(\mathrm{C} \equiv \mathrm{N}), 3209 \& 3344\left(\mathrm{NH}_{2}\right) ;{ }^{1} \mathrm{H}$ NMR (DMSO-d $\left.6, \delta, \mathrm{ppm}\right): 1.25$ (br, $\left.6 \mathrm{H}, \mathrm{C}_{-7} 2 \mathrm{CH}_{3}\right), 1.41\left(\mathrm{~s}, 3 \mathrm{H}, \mathrm{C}_{-9} \mathrm{CH}_{3}\right), 4.9$ (br, $2 \mathrm{H}, \mathrm{NH}_{2}, \mathrm{D}_{2} \mathrm{O}$ exchangeable), $5.31(\mathrm{~s}, 1 \mathrm{H}$, $\left.\mathrm{C}_{-8} \mathrm{H}\right)$, 7.25-7.69 (m, 4H, ArH). 
2-Amino-4-(m-nitrophenyl)-7,7,9-trimethyl pyrimidino[1',2':3,2] thiazolo[4,5b]pyridine-3-carbonitrile (3b)

IR $\left(\mathrm{cm}^{-1}, \mathrm{v}\right): 2189(\mathrm{C} \equiv \mathrm{N}), 3130 \& 3210\left(\mathrm{NH}_{2}\right) ;{ }^{1} \mathrm{H}$ NMR (DMSO-d $\left.\mathrm{d}_{6}, \delta, \mathrm{ppm}\right): 1.46$ (br, 6H, $\left.\mathrm{C}_{-7} 2 \mathrm{CH}_{3}\right), 1.62\left(\mathrm{~s}, 3 \mathrm{H}, \mathrm{C}_{-} \mathrm{CH}_{3}\right), 4.46\left(\mathrm{br}, 2 \mathrm{H}, \mathrm{NH}_{2}, \mathrm{D}_{2} \mathrm{O}\right.$ exchangeable), $5.17(\mathrm{~s}, 1 \mathrm{H}$, $\left.\mathrm{C}_{-8} \mathrm{H}\right), 7.64-7.79(\mathrm{~m}, 4 \mathrm{H}, \mathrm{ArH})$.

5-Substituted $-8,8,10$-trimethyl pyrimidino[1' $\left., 2^{\prime \prime}: 3^{\prime}, 2^{\prime}\right]$ thiazolo[4',5': 2,3]pyrido[2,3-d] pyrimidin-2,4-[1H, 3H]dithione derivatives $(5 \mathbf{a}, \mathrm{b})$.

General procedure: To a solution of o-aminonitrile $\mathbf{3 a}$ or $\mathbf{3 b}(0.01 \mathrm{~mol})$ in pyridine $(15 \mathrm{~mL})$, carbon disulfide $(0.05 \mathrm{~mol})$ was added and the reaction mixture was heated on a water bath for $10 \mathrm{~h}$. After cooling, ethanol was added and the separated solid was collected by filtration, dried and recrystallized to give compound $\mathbf{5 a}, \mathbf{b}$.

5-(p-Bromophenyl)-8,8,10-trimethyl pyrimidino $\left[1^{\prime \prime}, 2^{\prime \prime}: 3^{\prime}, 2^{\prime}\right]$ thiazolo $\left[4^{\prime}, 5^{\prime}: 2,3\right]$ pyrido [2,3-d]pyrimidine-2,4-[1H, 3H)dithione (5a).

IR $\left(\mathrm{cm}^{-1} \mathrm{v}\right): 3405$ (br, 2NH), 1230,1239(2C=S); $\left.{ }^{1} \mathrm{H}-\mathrm{NMR}-\mathrm{d}_{6}, \delta, \mathrm{ppm}\right): 1.24$ (br, 6H, $\left.\mathrm{C}_{-8} 2 \mathrm{CH}_{3}\right), 1.63\left(\mathrm{~s}, 3 \mathrm{H}, \mathrm{C}_{-10} \mathrm{CH}_{3}\right), 5.20\left(\mathrm{~s}, 1 \mathrm{H}, \mathrm{C}_{-9} \mathrm{H}\right), 7.36-7.70(\mathrm{~m}, 4 \mathrm{H}, \mathrm{ArH}), 12.77(\mathrm{br}, 2 \mathrm{H}$, $2 \mathrm{NH}, \mathrm{D}_{2} \mathrm{O}$ exchangeable)., ${ }^{13} \mathrm{C}$ NMR (DMSO- $\left.\mathrm{d}_{6}, \delta, \mathrm{ppm}\right): 28.55,28.79,30.57\left(3 \mathrm{CH}_{3}\right), 65.55$ $\left(\mathrm{C}_{-8}\right), 78\left(\mathrm{C}_{-9}\right), 124.17,124.34,125.98,126.58,128.56,129.32$ (ArC), 130. 80 (C-4a), 131.40 (C-5a), 134.71 (C-10), 135.35 (C-5), 142.55 (C-4b), 144.79 (C-5b), 148.19 (C-6a), $176.13,176.87(2 \mathrm{C}=\mathrm{S})$.

5-(m-Nitrophenyl)-8,8,10-trimethyl pyrimidino[1", $\left.2^{\prime \prime}: 3^{\prime}, 2^{\prime}\right]$ thiazolo $\left[4^{\prime}, 5 ': 2,3\right]$ pyrido [2,3-d] pyrimidin-2,4[1H,3H] dithione $(5 \mathrm{~b})$.

IR (cm $\left.{ }^{-1}, v\right): 3409(\mathrm{br}, 2 \mathrm{NH}), 1233,1241(2 \mathrm{C}=\mathrm{S}) ; \mathrm{MS} \mathrm{m} / \mathrm{z}(\%): 468$ (71).

\section{4-Substituted-7,7,9-trimethyl-1,3,4-trihydropyrimidino $\left[1^{\prime}, 2^{\prime}: 3,2\right]$ thiazolo[4,5-d]} pyrimidin-2-thione (6a-c).

General procedure: A mixture of compound 2a-c $(0.01 \mathrm{~mol})$ and thiourea $(0.01 \mathrm{~mol})$ was refluxed in absolute ethanol $30 \mathrm{~mL}$ and $5 \mathrm{~mL}$ of concentration hydrochloric acid for $6 \mathrm{~h}$. The solid product was filtered off dried and recrystallized to give compounds 6a-c.

4-(p-Bromophenyl)-7,7-9-trimethyl-1,3,4-trihydropyrimidino[1',2':3,2] thiazolo[4,5-d] pyrimidin-2-thione (6a).

IR $\left(\mathrm{cm}^{-1}, \mathrm{v}\right): 3166.8,3273.8(2 \mathrm{NH}), 1255(\mathrm{C}=\mathrm{S}) ;{ }^{1} \mathrm{H}-\mathrm{NMR}\left(\mathrm{DMESO}-\mathrm{d}_{6}, \delta, \mathrm{ppm}\right)$ : $1.24,1.25,1.5\left(3 \mathrm{~s}, 9 \mathrm{H}, \mathrm{C}_{-7} 2 \mathrm{CH}_{3}, \mathrm{C}_{-9} \mathrm{CH}_{3}\right), 4.99\left(\mathrm{~s}, 1 \mathrm{H}-\mathrm{C}_{-4} \mathrm{H}\right) 5.30\left(\mathrm{~s}, 1 \mathrm{H}, \mathrm{C}_{-8} \mathrm{H}\right), 7.47-7.61$ (m, 4H, ArH), 8.87 and 8.93 (2s, 2H, 2NH, $\mathrm{D}_{2} \mathrm{O}$ exchangeable); MS m/z (\%): 421 (17).

4-(m-Nitrophenyl)-7,7,9-trimethyl-1,3,4-trihydropyrimidino[1',2':3,2]thiazolo[4,5-d] pyrimidin-2-thione (6b).

${ }^{1} \mathrm{H}-\mathrm{NMR} \quad\left(\mathrm{DMSO}_{6}, \quad \delta, \quad \mathrm{ppm}\right) \quad 1.51,1.63,1.81 \quad\left(3 \mathrm{~s}, \quad 9 \mathrm{H}, \quad \mathrm{C}_{-7} \quad 2 \mathrm{CH}_{3}\right.$, $\left.\mathrm{C}_{-9} \mathrm{CH}_{3}\right), 4.97\left(\mathrm{~s}, 1 \mathrm{H}, \mathrm{C}_{-4} \mathrm{H}\right), 5.39\left(\mathrm{~s}, 1 \mathrm{H}, \mathrm{C}_{-8} \mathrm{H}\right), 7.51-7.64(\mathrm{~m}, 4 \mathrm{H}, \mathrm{ArH}), 8.91$ and $8.99(2 \mathrm{~s}$, $2 \mathrm{H}, 2 \mathrm{NH}, \mathrm{D}_{2} \mathrm{O}$ exchangeable) ${ }^{13} \mathrm{C}-\mathrm{NMR}$ (DMSO-d 6 , ppm): 24.01, 24.80, $26.95\left(3 \mathrm{CH}_{3}\right)$,

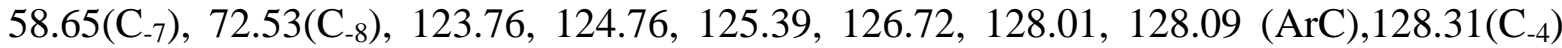
$128.54\left(\mathrm{C}_{-4 \mathrm{a}}\right), 128.82\left(\mathrm{C}_{-5 \mathrm{a}}\right), 130.25\left(\mathrm{C}_{-4 \mathrm{~b}}\right), 131.18\left(\mathrm{C}_{-9}\right), 173.43(\mathrm{C}=\mathrm{S})$.

4-(o-Chlorophenyl)-7,7,9-trimethyl-1,3,4-trihydropyrimidino[1',2':3,2] thiozolo[4,5-d] pyrimidine-2-thione (6c). 
IR $\left(\mathrm{cm}^{-1}, \mathrm{v}\right): 3341(\mathrm{br}, 2 \mathrm{NH}), 1249 .(\mathrm{C}=\mathrm{S}) ;{ }^{1} \mathrm{HNMR}$ (DMSO-d $\left.6, \delta, \mathrm{ppm}\right): 1.30,1.41$, $1.83\left(3 \mathrm{~s}, 9 \mathrm{H}, \mathrm{C}_{-7} 2 \mathrm{CH}_{3}, \mathrm{C}_{-9} \mathrm{CH}_{3}\right), 5.1\left(\mathrm{~s}, 1 \mathrm{H}, \mathrm{C}_{-4} \mathrm{H}\right), 5.50\left(\mathrm{~s}, 1 \mathrm{H}, \mathrm{C}_{-8} \mathrm{H}\right), 7.61-7.82(\mathrm{~m}, 4 \mathrm{H}$, ArH), 8.53 and $8.61\left(2 \mathrm{~s}, 2 \mathrm{H}, 2 \mathrm{NH}, \mathrm{D}_{2} \mathrm{O}\right.$ exchangeable).

\section{Ethyl 3,5-disubstituted-8,8,10-trimethyl pyrimidino[ $\left.1^{\prime}, 2^{\prime}: 3,2\right]$ thiazolo [4,5-d][1,2,4] triazolo[3,4-b]pyrimidine-1-carboxylate (10a,b).}

General procedure : A mixture of $\mathbf{6 b}, \mathbf{c}(0.01 \mathrm{~mol})$ and hydrazonyl chlorides $(0.01$ mol) was stirred under reflux in dry chloroform $(30 \mathrm{~mL})$ and $0.5 \mathrm{~mL}$ of triethylamine for 15h. the solvent was evaporated and the solid produced was washed three times by $30 \mathrm{~mL}$ ethanol, and crystallized to give (10a,b).

Ethyl 3-(p-tolyl)-5-(m, nitrophenyl)-8,8,10-trimethyl pyrimidino $\left[1^{\prime}, 2^{\prime}: 3,2\right]$ thiazolo $[4,5-$ d] $[(1,2,4]$ triazolo $)[3,4-b]$ pyrimidin-1-carboxylate (10a).

It was obtained from $\mathbf{6 b}$ and ethyl chloro-(p-tolyl hydrazono) acetate, IR $\left(\mathrm{cm}^{-1}, v\right)$ : 1748(CO); ${ }^{1} \mathrm{H}$ NMR (DMSO-d $\left.\mathrm{d}_{6}, \delta, \mathrm{ppm}\right): 1.24\left(\mathrm{t}, \mathrm{J}=7.5 \mathrm{~Hz}, 3 \mathrm{H}, \mathrm{CH}_{3}\right), 1.42(\mathrm{br}, 6 \mathrm{H}, \mathrm{C}-$ $\left.{ }_{8} 2 \mathrm{CH}_{3}\right), 1.81,2.07\left(2 \mathrm{~s}, 6 \mathrm{H}, \mathrm{C}-{ }_{10} \mathrm{CH}_{3}, \mathrm{CH}_{3}\right), 4.17\left(\mathrm{q}, \mathrm{J}=7.5,2 \mathrm{H}, \mathrm{CH}_{2}\right), 4.96\left(\mathrm{~s}, 1 \mathrm{H}, \mathrm{C}_{5}-\mathrm{H}\right)$, $5.33\left(\mathrm{~s}, 1 \mathrm{H}, \mathrm{C}_{9}-\mathrm{H}\right), 7.67-7.97(\mathrm{~m}, 8 \mathrm{H}, 2 \mathrm{ArH})$.

Ethyl-3-phenyl-5-(o-chlorophenyl)-8,8,10-trimethyl-pyrimidino[1',2':3,2]thiazolo[4,5-d] $([1,2,4]$ triazolo) $[3,4-b]$ pyrimidine1-carboxyalte $(10 b)$.

It was obtained form $\mathbf{6 c}$ and ethyl chloro(phenyl hydrazono)-acetate, IR $\left(\mathrm{cm}^{-1}, \mathrm{v}\right)$ : 1741 (CO); ${ }^{1} \mathrm{H}-\mathrm{NMR}$ (DMSO-d 6 , $\delta, \mathrm{ppm}$ ): 1.26 (t, J=7.8 Hz, 3H, $\mathrm{CH}_{3}$ ), 1.42 (br, 6H, C. $\left.{ }_{8} 2 \mathrm{CH}_{3}\right), 1.87\left(\mathrm{~s}, 3 \mathrm{H}, \mathrm{C}_{-10} \mathrm{CH}_{3}\right), 4.19\left(\mathrm{q}, \mathrm{J}=8 \mathrm{~Hz}, 2 \mathrm{H}, \mathrm{CH}_{2}\right), 4.7\left(\mathrm{~s}, 1 \mathrm{H}, \mathrm{C}_{5}-\mathrm{H}\right), 5.36(\mathrm{~s}, 1 \mathrm{H}, \mathrm{C}$. $9-\mathrm{H})$, 7.69-7.97 (m, 9H, 2ArH).

\section{2-(4-(m-Nitrophenyl)-7,7,9-trimethyl-1,4-dihydro-pyrimidino[1',2':3,2] thiazolo[4,5-d]} pyrimidin-2-yl sulfanyl)-ethanol (13).

A solution of compound $\mathbf{6 b}(0.01 \mathrm{~mol})$ and sodium hydroxide $(0.01 \mathrm{~mol})$ in ethanol $(30 \mathrm{~mL})$ was treated with 2-chloroethanol $(0.01 \mathrm{~mol})$ and the reaction mixture was refluxed for $16 \mathrm{~h}$. the formed precipitate was filtered off, dried and recrystalized to give compound (13) IR $\left(\mathrm{cm}^{-1}, \mathrm{v}\right): 3200-3420(\mathrm{NH} / \mathrm{OH}) ;{ }^{1} \mathrm{H}-\mathrm{NMR}$ (DMSO-d $\left.6, \delta, \mathrm{ppm}\right): 1.60\left(\mathrm{br}, 6 \mathrm{H}, \mathrm{C}_{-7} 2 \mathrm{CH}_{3}\right)$, $2.07\left(\mathrm{~s}, 3 \mathrm{H}, \mathrm{C}_{-9} \mathrm{CH}_{3}\right), 4.19-4.21\left(\mathrm{~m}, 4 \mathrm{H}, 2 \mathrm{CH}_{2}\right), 5.01$ (s, $1 \mathrm{H}, \mathrm{OH}, \mathrm{D}_{2} \mathrm{O}$ exchangeable), 5.1 (s, $\left.1 \mathrm{H}, \mathrm{C}_{-4} \mathrm{H}\right), 5.5\left(\mathrm{~s}, 1 \mathrm{H}, \mathrm{C}_{-8} \mathrm{H}\right), 7.6-7.73(\mathrm{~m}, 4 \mathrm{H}, \mathrm{ArH}), 8.37\left(\mathrm{~s}, 1 \mathrm{H}, \mathrm{NH}, \mathrm{D}_{2} \mathrm{O}\right.$ exchangeable)

2-(2-Cyanoetheyl sulfanyl)-7,7,9-trimethyl -4-(m-nitrophenyl) 1,4-dihydropyrimidino $\left[1^{\prime}, 2^{\prime}: 3,2\right]$ thiazolo $[4,5-d]$ pyrimidine (14).

A mixture of compound $\mathbf{6 b}(0.01 \mathrm{~mol})$, acrylonitrile $(0.01 \mathrm{~mol})$ and triethylamine two drops in ethanol $(50 \mathrm{~mL})$ was heated under reflux for $3 \mathrm{~h}$, cooled, filtered, dried and recrystallized to give compound 14. IR $\left(\mathrm{cm}^{-1}, \mathrm{v}\right): 2243(\mathrm{C} \equiv \mathrm{N}), 3341(\mathrm{NH})$ groups; ${ }^{1} \mathrm{H}$ NMR $\left(\mathrm{DMSO}_{6}, \delta, \mathrm{ppm}\right): 1.31,1.41,1.72\left(3 \mathrm{~s}, 9 \mathrm{H}, \mathrm{C}_{-7} 2 \mathrm{CH}_{3}, \mathrm{C}_{-9} \mathrm{CH}_{3}\right), 3.2\left(\mathrm{t}, 2 \mathrm{H}, \mathrm{SCH}_{2}\right), 3.82$, (t, $\left.2 \mathrm{H}, \mathrm{CH}_{2} \mathrm{CN}\right), 5.11\left(\mathrm{~s}, 1 \mathrm{H}, \mathrm{C}_{-4} \mathrm{H}\right), 5.51\left(\mathrm{~s}, 1 \mathrm{H}, \mathrm{C}_{-8} \mathrm{H}\right), 7.67-7.82(\mathrm{~m}, 4 \mathrm{H}, \mathrm{ArH}), 8.61(\mathrm{~s}, 1 \mathrm{H}$, $\mathrm{NH}, \mathrm{D}_{2} \mathrm{O}$ exchangeable).

\section{Synthesis of compounds 15 and 16}

Compound 6b (0.01 mol) and salicyladehyde or 7-hydroxy-5-methoxy-2-oxobenzopyran-6-carboxaldehyde $(0.01 \mathrm{~mol})$ were refluxed in ethanolic piperidine $(30 \mathrm{ml})$ for $30 \mathrm{~min}$. The solid product was filtered, dried and recrystalized to give compounds $\mathbf{1 5}$ and $\mathbf{1 6}$.

3-(7,7,9-Trimethyl-1,4-dihydropyrimidino)[1',2':3,2] thiazolo[4,5-d] pyrimidin-2-yl sulfanyl methyl)-2-iminobenzopyran(15). 
IR $\left(\mathrm{cm}^{-1}, \mathrm{v}\right): 3415(2 \mathrm{NH}) ;{ }^{1} \mathrm{H}-\mathrm{NMR}\left(\mathrm{DMSO}_{6}, \delta, \mathrm{ppm}\right): 1.23\left(\mathrm{br}, 6 \mathrm{H}, \mathrm{C}_{-7} 2 \mathrm{CH}_{3}\right.$ ), $1.62\left(\mathrm{~s}, 3 \mathrm{H}, \mathrm{C}_{-9} \mathrm{CH}_{3}\right), 2.39\left(\mathrm{~s}, 2 \mathrm{H}, \mathrm{SCH}_{2}\right), 4.98\left(\mathrm{~s}, 1 \mathrm{H}, \mathrm{C}_{-4} \mathrm{H}\right) 5.52\left(\mathrm{~s}, 1 \mathrm{H}, \mathrm{C}_{-8} \mathrm{H}\right), 6.4(\mathrm{~s}, 1 \mathrm{H}$, pyran $\mathrm{H}), 7.36-7.70\left(\mathrm{~m}, 9 \mathrm{H}, 2 \mathrm{ArH}+\left(\mathrm{NH}, \mathrm{D}_{2} \mathrm{O}\right.\right.$ exchangeable $), 11.2\left(\mathrm{br}, 1 \mathrm{H},=\mathrm{NH}, \mathrm{D}_{2} \mathrm{O}\right.$ exchangeable)

3-(7,7,9-Trimethyl-1,4-dihydropyrimidino[1',2':3,2] thiazolo[4,5-d] pyrimidin-2-yl sulfanyl methyl)-2-imino-5-methyoxybenzo[1,2-b:5,4-b']dipyran-8-one (16)

IR $\left(\mathrm{cm}^{-1}, \mathrm{v}\right): 1731(\mathrm{C}=\mathrm{O}), 3342(2 \mathrm{NH}) ;{ }^{1} \mathrm{H}-\mathrm{NMR}\left(\mathrm{DMSO}_{6}, \delta, \mathrm{ppm}\right): 1.60,1.62$, $1.72\left(3 \mathrm{~s}, 9 \mathrm{H}, \mathrm{C}-72 \mathrm{CH}_{3}, \mathrm{C}_{-9} \mathrm{CH}_{3}\right), 2.48\left(\mathrm{~s}, 2 \mathrm{H}, \mathrm{SCH}_{2}\right), 3.88\left(\mathrm{~s}, 3 \mathrm{H}, \mathrm{OCH}_{3}\right), 5.01\left(\mathrm{~S}, 1 \mathrm{H}, \mathrm{C}_{-4} \mathrm{H}\right)$ $5.79\left(\mathrm{~s}, 1 \mathrm{H}, \mathrm{C}_{-8} \mathrm{H}\right), 7.3\left(\mathrm{~s}, 1 \mathrm{H}, \mathrm{C}_{-4}\right.$ pyran $), 7.80-8.4\left(\mathrm{~m}, 8 \mathrm{H}, \mathrm{ArH}, \mathrm{C}_{-6} \mathrm{H}\right.$ pyran $+\mathrm{C}_{-7}$ pyran + $\left(\mathrm{NH}, \mathrm{D}_{2} \mathrm{O}\right.$ exchangeable), $10.14\left(\mathrm{~s}, 1 \mathrm{H},=\mathrm{NH}, \mathrm{D}_{2} \mathrm{O}\right.$ exchangeable $)$.

4-(-m-Nitrophenyl)-7,7,9-trimethyl-1,4-dihydropyrmi-dino [1',2':3,2]thiazolo[4,5-d] pyrimidin-2-ylsulfanyl)-2-[4-(m-nitro-phenyl)-7,7,9-trimethyl-1,4dihydropyrimidino $\left[1^{\prime}, 2 ': 3,2\right]$ thiazolo $[4,5-d]$ pyrimidin-2-yl sulfanyl)ethanethioate (17).

A mixture of compound $\mathbf{6 b}(0.01 \mathrm{~mol})$, chloroacetyl chloride $(0.01 \mathrm{~mol})$ and triethylamine two drops in dimethyl formamide $(30 \mathrm{ml})$ was heated under reflux for $3 \mathrm{~h}$, the solid product was filtered, dried and recrystallized to give compound 17. IR $\left(\mathrm{cm}^{-1}, \mathrm{v}\right): 1671$

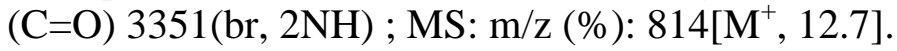

\section{Cytotoxicity assay:}

The cells were propagated in Dulbecco's modified Eagle's medium (DMEM) supplemented with $10 \%$ heat-inactivated fetal bovine serum, $1 \%$ L-glutamine, HEPES buffer and 50ug/ml gentamycin. All cells were maintained at $37^{\circ} \mathrm{C}$ in a humidified atmosphere with $5 \% \mathrm{CO}_{2}$ and were subcultured two times a week.

Cell toxicity was monitored by determining the effect of the test samples on cell morphology and cell viability.

Cytotoxicity evaluation using viability assay: For cytotoxicity assay, the cells were seeded in 96-well plate at a cell concentration of $1 \times 10^{4}$ cells per well in $100 \mu 1$ of growth medium. Fresh medium containing different concentrations of the test sample was added after $24 \mathrm{~h}$ of seeding. Serial two-fold dilutions of the tested chemical compound were added to confluent cell monolayers dispensed into 96-well, flat-bottomed microtiter plates (Falcon, NJ, USA) using a multichannel pipette. The microtiter plates were incubated at $37^{\circ} \mathrm{C}$ in a humidified incubator with $5 \% \mathrm{CO}_{2}$ for a period of $48 \mathrm{~h}$. Three wells were used for each concentration of the test sample. Control cells were incubated without test sample and with or without DMSO. The little percentage of DMSO present in the wells (maximal 0.1\%) was found not to affect the experiment. After incubation of the cells for $24 \mathrm{~h}$ at $37^{\circ} \mathrm{C}$, various concentrations of sample $(50,25,12.5,6.25,3.125 \& 1.56 \mathrm{Vig})$ were added, and the incubation was continued for $48 \mathrm{~h}$ and viable cells yield was determined by a colorimetric method.

In brief, after the end of the incubation period, media were aspirated and the crystal violet solution $(1 \%)$ was added to each well for at least 30 minutes. The stain was removed and the plates were rinsed using tap water until all excess stain is removed. Glacial acetic acid (30\%) was then added to all wells and mixed thoroughly, and then the absorbance of the plates were measured after gently shaken on Microplate reader (TECAN, Inc.), using a test wavelength of $490 \mathrm{~nm}$. All results were corrected for background absorbance detected in wells without added stain. Treated samples were compared with the cell control in the absence of the tested compounds. All experiments were carried out in triplicate. The cell cytotoxic effect of each tested compound was calculated (Mosmann, 1983; Vijayan et al., 2004). 


\section{References :}

Abdelhamid, A.O.; Ismail, Z. H.; Abdel-Aziem, A. (2007): Reactions with hydrazonyl halides $60^{1}$ : synthesis of thieno [2',3':4,5] pyrmidino[1,2-b][1,2,4,5]tetrazines, [1] benzothieno[2',3':4,5]pyrimidino[1,2-b][1,2,4,5]tetrazines, pyrazolo[3,',4':4,5] pyrimidino[1,2-b] $[1,2,4,5]$ tetrzines and pyrazolo [2,4]d] pyridazines Jorunal of chemical Research, 10, 609-616.

Adel-Megeid, F.M.E.; Heikal, O.A.; El-Nezhawy, A.O.H.; Rashad, A.E.; El-Nezhawy, A.O.H.; (2005): Synthesis and iosmerization of thienotriazolopyrimidine and thienotetrazolo pyrimidine derivative with potential anti-inflammatory activity Heteroatom Chem., 16, 226-234.

Alagarsamy, V.; Shankar,D.; Meena,S.; Thirumurugan K.; Durai, A.K.T.(2007): Drug Development Res., 68: 134-412.

Ammar, Y.A., Ismail,M.M.; . El-Gaby S.A.; . Zahran, M.A. (2002): Indian J. Chem., 4IB: 1486-1490.

Amr, A.E.; Hegab, M.I.; Ibrahim A.A.; Abdalah, M.M. (2003): Synthesis and reactions of some fused oxazinone, pyrimidinone, thiopyrimidnone and triazinone derivatives with thiophene ring as analgesic, anticonvulsant and anti-Parkinsonian agents. Monatsh. Chem., 134: 1395-1409.

Amr, A.E.; Mohamed, A.M.; Mohamed, S.F.; Abdel-Hafez N.A.; Hammam, A.G. (2006): Synthesis and anticancer activities of new pyridine, pyrane and pyrimidine derivatives fused with nitrobenzosubetrone moiety. Bioorg. Med. Chem., 14: 5481-5488.

Baxter, A.; Cooper A.; Kinchin E.; Moakes K.; J. Unitt; A. Wallace (2006): Bioorg. Med. Chem. Lett., 16, 960-963

Beek, J.P.; Curry, M.A.; Chorvat, R.J.; Fitzgerald, L.W. (1999): Bioorg. Med. Chem. Lett., 9, 1185-1188.

Bekhit, A. A.; Fahmy H. T. Y.; Rostom S. A. F.; Baraka A. M., (2003): Eur. J. Med. Chem., 38, 27-36.

Fahmy, H. T. Y.; Rostom S. A. F.; Saudi, M. N.; Zjawiony, J. K.; Robins D. J. (2003): Arch. Pharm. Pharm. Med. Chem., 336, 216-225.

Hafez, H.N.; Hussein, H.A. R.; El-Gazzar, A.B. (2010): Synthesis of substituted thieno[2,3-d]pyrimindine-2,4-dithiones and their S-glucoside analogues as potential antiviral and antibacterial agents. European Journal of Medicinal Chemistry 4026-4034.

Hamman, Abou-El-Fotooh G.; Ali, Mohamed I. (1981): Synthesis and reactions of 2,3dihydro-7H-6,styryl-7,7,-dimethyl thiazolo [3,2-a] pyrimidin-3-ones. J. Chem. Eng. Data 26,99-100.

Hegab, M.I.; Rashad, A.E.; Shamroukh, A.H.; Hamza,LA. (2006): J. Sulfur Chem., 27: 213-224.

HO, Y.W., (2003): J. Chin. Chem. Soc., 50: 293-200.

Kini, G. D.; Anderson, J. D.; Sanghvi, Y. S.; Lewis A. F.; Smee, D. F.; Revankar, G. R.; Robins, R. K.; Cottam H. B. (1991): J. Med. Chem., 34, 3006-3010. 
Lewis A. F; . Revankar G. R; Fennanwald S. M.; Huffman J. H.; Rando, R. F. (1995): J. Heterocyclic Chem., 32, 547-556.

Mosmann, T. (1983): Rapid colorimetric assay for cellular growth and survival: application to proliferation and cytotoxicity assays. J. Immunol. Methods; 65: 55-63.

Nagahara, K.; Anderson J. D.; Kini, G. D.; Dalley, N. K.; S. B. Larson; D. F. Smee, A.; Jin; B. S. Sharma, W.B.; Jolley; R.; K.; Robins, Cottam, H. B.; (1990): J. Med. Chem., 22, 407-415.

Rashad, A.E.; Shamroukh, A.H.; Ali, M.A; Abdel-Motti, F.M. (2007): Heteroatom Chem., 18: 274-282.

Rashad, A.E.; Sayed, H.H.; Shamroukh, A.H.; Awad, H.M.; (2005): Preparation of some fused pyridopyriminde and pyridothienotriazine derivatives for biological evaluation. Phosphorus, Sulfer Silicon Relat. Elem. 180, 2767-2777.

Rashad,

$$
\text { A.E.; Shamroukh, A.H.; }
$$

Abdel-Megeid

R.E.; El-Sayed, W.A. (2010): Synthesis, reactions and antimicrobial evaluation of some polycondensed thienopyrimidine derivatives, Synthetic Communications, 40: 1149-1160.

Shamrokh, Ahmed H.; Marzouk Nermen A.; Al-Saadny Abeer H.; Micky Jihan A.; AbdelMegeid Farouk M.E. (2010): Anti-H5N1 Evaluation of some newly synthesized indenothienopyridine derivatives, World Journal of Chemistry 5(1): 37-43.

Shishoo, C.J.; Shirsath, V.S.; Rothod I.S.; Yande, V. (2000): Eur. J. Med. Cham., 35: 351-356.

Shishoo, C.J.; Shirsath, I.S.R.; Yande, V. (2000): Eur. J. Med. Chem., 35, 391-356.

Takeshima, T.; Imamato, T.; Tokoyama, M.; Yamamoto, K.; Akana, M. (1968): J. Org. Chem. 33, 2877.

Vijayan, P.; Raghu, C; Ashok, G.; Dhanaraj, S.A. Suresh, B. (2004): Antiviral activity of medicinal plants of Nilgiris. Indian J. Med. Res. 120: 24-29.

Wagnat, W.W.; Ommar, M.E.; Abdel-Salam E.; Gamal,A.E. (2008): Acta Pharm., 58: 114.

Walters, C. Austin; R. Bonnert, P., Cage, M.; Christie, M.; Ebden, S. Gardiner, C.; Grahmes, S.; Hill, F.; Hunt; R.; Jewell, S. (2007): Bioorg. Med. Chem. Lett.7, 17, 2731-2734. 


\section{تثشييد، تفاعلات ومضادات خلايا الأورام لبعض مشتقات السيازولو بريمدين}

$$
\text { نرمين عبدالله مرزوق السعداوي }
$$

$$
\text { قسم الكيمياء - كلية العلوم (بنات) - جامعة الأزهر - مدينة نصر - القاهرة - مصر }
$$

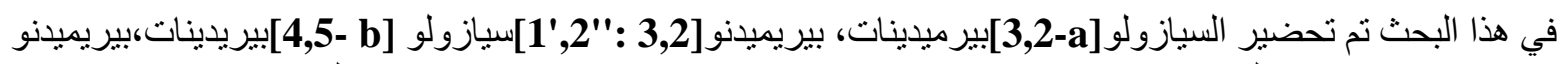

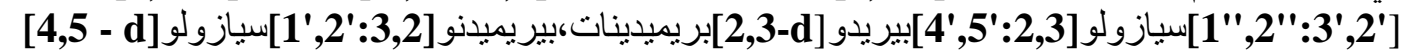

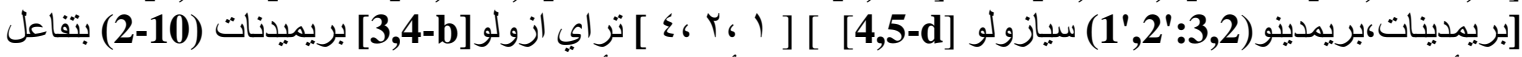

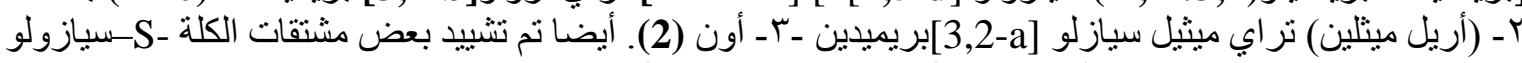

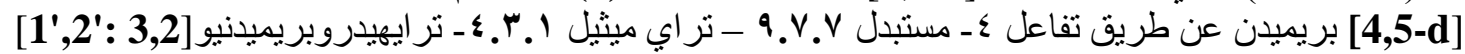

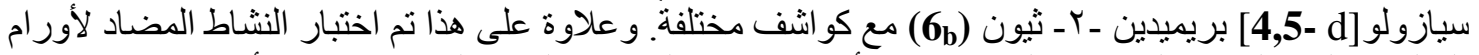

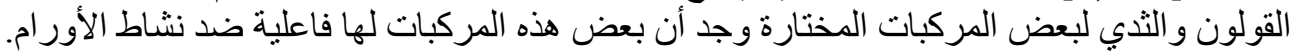


